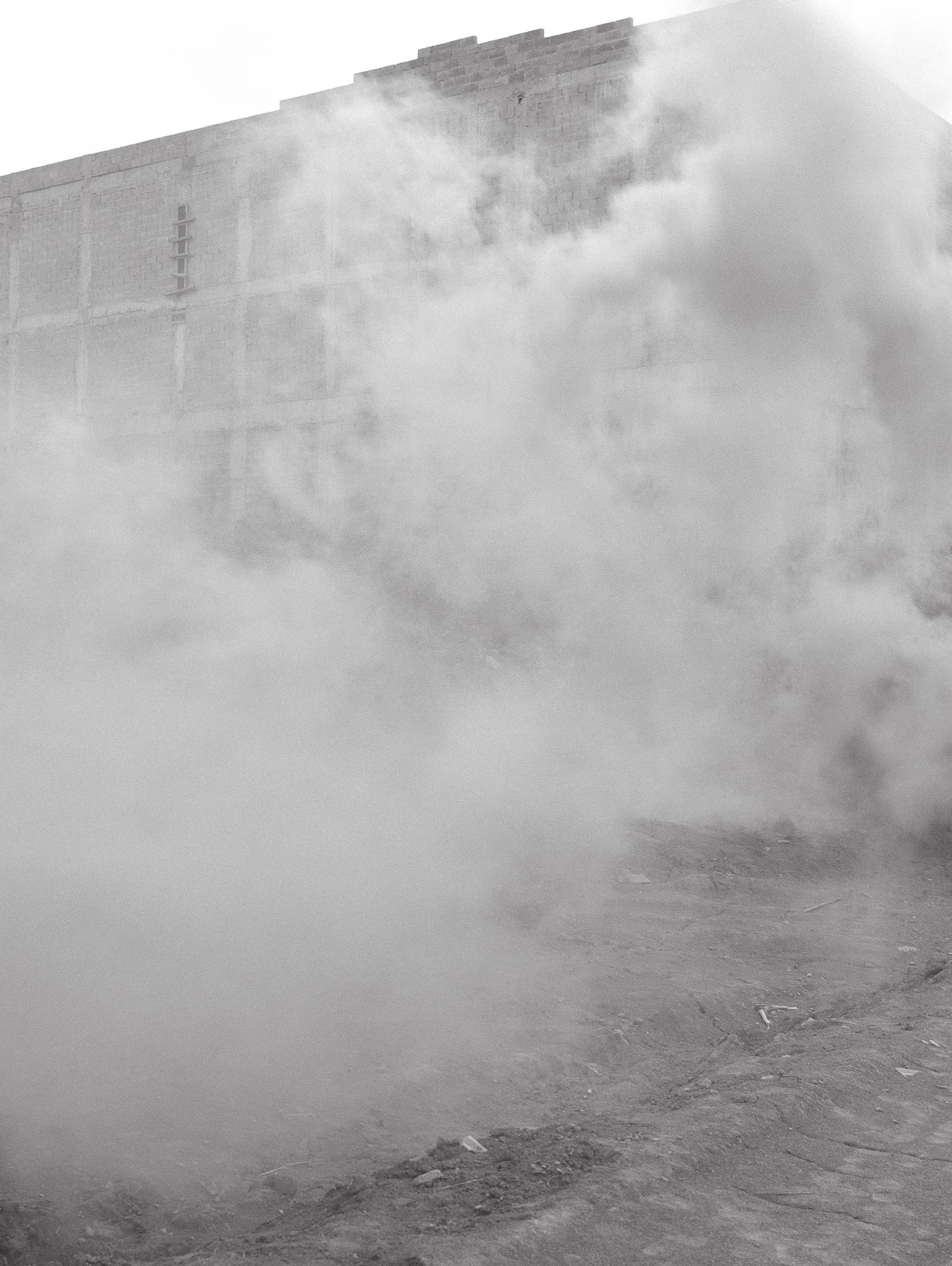




\title{
DO PROTESTO AO PLEBISCITO: UMA AVALIAÇÃO CRÍTICA DA ATUAL CONJUNTURA BRASILEIRA
}

\author{
FABIANO SANTOS
}

Os brasileiros que agora adentram a meia-idade começaram sua vida adulta durante o período militar. Iniciaram, portanto, sua socialização política em meio a uma ditadura, regime que resultou de um golpe civil e militar desferido em 1964 contra o governo de João Goulart e as instituições representativas criadas em 1946. A crise que antecedeu o evento se explica em boa medida pelo processo de radicalização política a envolver os principais atores da cena brasileira à época. À esquerda, facções no interior de alguns partidos de orientação socialista e trabalhista, sindicatos, estudantes e segmentos minoritários das Forças Armadas confrontavam, à direita, facções no interior de partidos conservadores, empresários, o grosso das Forças Armadas, classes médias e principais órgãos de imprensa. Embora afastados quanto a valores, interesses e visões de mundo, algo unia tais contendores: o desprezo pelas instituições da democracia representativa e seu mecanismo principal, o voto popular. À esquerda e à direita, uma visão negativa, profundamente negativa, prevalecia sobre o modo pelo qual operava o sistema político, sobretudo, o Congresso Nacional. Instituição, para uns, sede de uma elite atrasada e ponto de veto às reformas necessárias para tornar o país mais justo; para outros, corrupta, clientelista, responsável pela irracionalidade no gasto e nas contas públicas. O golpe, como é sabido, veio e com ampla vantagem para as forças da direita política.

[1] Por óbvio, o mais grave efeito do regime militar consistiu no enorme montante de vidas sacrificadas pelos assassinatos e torturas perpetrados pelo aparelho repressivo do Estado. Todavia, não é objetivo do presente artigo discorrer sobre esse trágico e fundamental aspecto da ditadura cujas consequências ainda se farão sentir por muitas gerações.
Qual foi o legado do período ditatorial'? No início dos anos 1980, do ponto de vista político, direitos básicos, como os de livre associação, manifestação, discordância, além da permanência de várias limitações ao exercício do voto, eram severamente restritos. No âmbito macro, Judiciário e Legislativo, estados e municípios, partidos e candidatos se viam praticamente indefesos perante um Executivo federal hipertrofiado e sempre disposto a intervir nas instituições de forma a impedir dinâmicas políticas eventualmente contrárias aos seus desígnios. Do ponto de vista econômico, o quadro se compunha de inflação galopante, sempre acima de dois dígitos, extrema vulnerabilidade externa, crises cambiais recorren- 
tes, além de depressão, redução do PIB e aumento do desemprego. Finalmente, do ponto de vista social, exclusão, analfabetismo, desigualdade e pobreza crescentes e um cenário de mobilidade estagnado. Com alguma variação em algum dos diversos indicadores, em um ano ou outro, além de algum ensaio de descompressão aqui e ali, a visão geral de quem acordava para a vida adulta, de fato, não era nada alentadora.

A democracia e o clamor pela restauração das liberdades civis e políticas, pela volta da competição partidária plena e aberta, pelas eleições diretas para todos os cargos de representação e de chefia do Poder Executivo em todos os níveis tornaram-se o grande desiderato da geração que hoje inicia sua maturidade. Não apenas a democracia, mas também os resultados esperados do exercício do voto em larga escala, do exercício da crítica, da tolerância, da livre manifestação do pensamento, da resolução pacífica e institucionalizada de conflitos. A duras penas a transição foi alcançada e realizada. Com muito esforço e engenho político se elegeu uma assembleia constituinte, se desenhou e promulgou uma nova Constituição. Vitórias e testes importantes foram experimentados pelas instituições recém-criadas, por exemplo, quando, logo após exercer o voto direto para a escolha de seu presidente, a nação se vê compelida a destituir, dentro do marco legal, seu primeiro mandatário escolhido 29 anos após a eleição de Jânio Quadros.

Cerca de trinta anos mais tarde, é o momento de fazer um balanço do que se alcançou a partir da transição para a democracia. Qual seria o legado, também de uma perspectiva ampla, do livre funcionamento das instituições do governo representativo? Por definição, os obstáculos políticos existentes durante a ditadura foram removidos, pois do contrário não estaríamos a falar de legado democrático. Do ponto de vista econômico, temos a retomada do crescimento (tendo sido raros os anos de recessão ou declínio), inflação de um dígito há quase vinte anos, redução drástica da vulnerabilidade externa, aumento consistente do emprego e da renda, sobretudo das camadas mais pobres. Do ponto de vista social, embora ainda longe de alcançar patamares razoáveis de qualidade, educação e saúde públicas massificadas, redução significativa nos indicadores de pobreza e desigualdade, além de um quadro de crescente mobilidade.

Se essa síntese histórica é verossímil, a questão que se coloca de imediato no atual cenário de conturbação e agitação políticas refere-se ao grau de inconformismo demonstrado nas ruas relativamente ao funcionamento das instituições políticas brasileiras. Por que tanta revolta, sentimento que se fez sentir em toda sua agudeza ao longo do mês de junho de 2013 ? 


\section{AS MANIFESTAÇõES}

As manifestações de junho de 2013 marcarão para sempre a consciência cívica e a socialização política dos brasileiros. Os manifestantes foram às ruas para protestar, inicialmente em São Paulo, contra o aumento no preço das passagens de ônibus. A inabilidade das autoridades locais no trato da questão, sobretudo pela subestimação do potencial de conflito que lhe era inerente, além da violência policial com a qual foram tratados estudantes e jornalistas que cobriam os primeiros eventos, tornaram algo que tudo tinha de tópico e passageiro em fenômeno político de grandes proporções. A sequência dos acontecimentos tem sido repetida à exaustão: estudantes e ativistas, pelas redes sociais, essa nova tecnologia de mobilização da ação coletiva, passaram a conclamar seguidores para protestar contra, além do reajuste no custo do transporte, a truculência do aparato repressivo paulista, sem deixar de sugerir, ao mesmo tempo, eventual incorporação de novas bandeiras às manifestações (por motivos ainda desconhecidos, a derrubada da PEC 37, em tramitação no Congresso e prestes a ser votada na Câmara, surgiu como principal sugestão de pauta adicional). Os seguidores atingidos passaram a estimular mais "amigos", os quais, por sua vez, agregaram novas pautas e justificativas para a expressão de inconformismo e revolta. A grande imprensa, aturdida, de início denunciou aquilo que lhe pareceu obra dos jovens revolucionários de sempre, acrescidos de um sem-número de rebeldes sem causa; em pouco tempo, no entanto, mudou seu discurso e passou a cobrir os protestos como rito de passagem cívico quase obrigatório.

Não foi surpreendente a inclusão do tema da corrupção na pauta dos protestos. Em algum momento haveria de aparecer, sobretudo pelo fato de o país estar sediando a Copa das Confederações, evento organizado pela FIFA, alvo de investigações de suborno a envolver até então respeitáveis homens públicos brasileiros. Inusitada acabou sendo a coalizão social formada de maneira, por assim dizer, "espontânea", nas ruas. Uma coalizão a congregar militantes do Movimento pelo Passe Livre (MPL); jovens e não tão jovens radicais de esquerda, filiados a partidos como PSOL e PSTU; ativistas de causas sociais as mais diversas (índios, LGBT, negros etc.); segmentos das classes alta, média alta e da nova classe média; órfãos de alternativas partidárias consistentes à direita do espectro político; anarquistas e ativistas conectados a movimentos internacionais de protesto; além de neonazistas e fascistas assumidos, adeptos da violência e da intolerância como meios legítimos de manifestação e expressão de preferências e valores. Desprovidos de uma reivindicação específica, como nos episódios das "Diretas 
já" ou do impeachment do presidente Fernando Collor, encontravam-se todos ligados numa mesma emoção: participar, protestar, se expressar, eventualmente de forma violenta, gritar palavras de ordem, portar cartazes, vestir máscaras, enfim, sentir a euforia de fazer parte de um movimento de massa de proporções inéditas.

A estratégia dos ativistas iniciais, conjunto formado pelo MPL, membros dos partidos da esquerda radical e ativistas profissionais, conectados aos movimentos de protesto internacionais, acabou sendo extremamente bem-sucedida. O timing da Copa das Confederações garantiu cobertura ampla da imprensa nacional e internacional aos eventos. Obra de gênio político, por certo, foi a associação, como se houvesse um trade-off, entre os gastos realizados para a renovação dos estádios e da infraestrutura mínima necessária à viabilização dos jogos e a secular dificuldade no fornecimento de serviços públicos universais de qualidade em áreas vitais como educação e saúde. Ativar o tema da corrupção, através da bandeira da PEC 37, como tela de fundo acabou por completar o serviço. Simples, primário e eficaz.

Mas, se a ativação do tema da corrupção não foi surpreendente, os ensaios de aproximação das ruas com o fascismo ${ }^{2}$ assustou bastante, e não apenas os espectadores das manifestações, aqueles que acabaram optando por não mudar o Brasil mediante a imposição de transtornos à vida alheia3. Boa parte dos manifestantes, principalmente aqueles vinculados a partidos políticos, em geral de orientação esquerdista, sofreram duro revés ao se perceberem lado a lado com cartazes a expor dizeres do tipo "Ditadura já", "O povo unido não precisa de partido" e assemelhados. No dia 20 de junho, uma quinta-feira, militantes de partidos políticos e sindicatos tentaram participar de manifestações. Tiveram suas bandeiras e cartazes destruídos e foram fisicamente agredidos.

Àquela altura, vários governos estaduais e municipais, incluindo os de São Paulo, nascedouro da crise, já haviam cancelado os aumentos nas tarifas de ônibus. Por óbvio, o fenômeno extrapolava em muito a intenção inicial dos manifestantes. Percebido o problema pelo núcleo inicial de manifestantes, tratar-se-ia agora de uma questão de "disputar o significado das ruas". A palavra de ordem dos entusiastas das manifestações tornou-se então não permitir que os fascistas dominassem a cena, não permitir que a direita política prevalecesse na tradução do sentimento difuso de insatisfação e inconformismo e canalização da nova energia societal brasileira. Tarde demais: o estrago já estava feito. A equação fascista, antes apenas recôndita nas mentes de segmentos da elite, leitores de diários cariocas e paulistas, agora é clara e despudoradamente verbalizada em nossa common parlance.

\begin{abstract}
[2] Uso os termos "fascismo" $\mathrm{e}$ "protofascismo" de maneira assumidamente pouco rigorosa. Com eles, quero designar uma atitude política autoritária cuja essência consiste em não reconhecer a pluralidade de interesses e opiniões existentes na sociedade como algo legítimo. A princípio, o alvo da atitude fascista, como na experiência italiana e alemã do período que antecede a Segunda Guerra Mundial, são os partidos e o governo representativo. A pluralidade partidária, baseada no voto popular, é vista como um mal a ser extirpado, posto que baseado na delegação de poder feita de forma equivocada por seres inferiores, o povo. A apologia da democracia direta e da imposição da vontade via manifestações violentas e depredações é o corolário comportamental dessa atitude. Depredações, ataques ao comércio e prédios públicos são as formas mais patológicas de tal comportamento.
\end{abstract}

[3] Em tom ao mesmo tempo autocrítico e triunfalista, um dos cartazes mais interessantes dos protestos dizia: "Desculpem o transtorno, estamos mudando o Brasil". 
A equação fascista brasileira é tão simples e primária quanto a ideia de que educação e saúde no Brasil vão mal porque o governo gastou muito nas obras dos estádios onde serão realizadas as partidas da Copa do Mundo de 2014. Segundo o argumento, o problema brasileiro é político, ou melhor, é "a política" ou são "os políticos". No Brasil, dirigentes eleitos, partidos, candidatos, governantes, responsáveis pela chefia do Poder Executivo no âmbito municipal, estadual e federal seriam todos corruptos. Evidentemente, mais grave seria a situação do Congresso Nacional, das Assembleias Legislativas e das Câmaras Municipais. Tratar-se-ia de quadrilhas organizadas para assaltar os cofres públicos. As instituições "formais" de controle, sobretudo o Poder Judiciário e o Ministério Público, embora em geral compostos de homens preparados e de bem, encontrar-se-iam desprovidas dos instrumentos necessários para evitar a permanente prática de crimes contra o erário e a boa-fé do cidadão comum. Mecanismo clássico da democracia e de regulação da conduta dos agentes públicos, o voto, em terra brasileira, nada mais seria do que fator determinante a ensejar um cenário de decadência e degradação institucional. Dado que a esmagadora maioria da população é pobre e ignorante, beneficiária de rendas e serviços transferidos pelo governo, pela máquina pública, corrupta em sua origem, o eleitor, na verdade, seria, em última instância, cúmplice da engrenagem. $\mathrm{Na}$ equação fascista, em outras palavras, o voto popular estaria na raiz mesma do nosso problema político.

No fundo, e os idos dos anos 1960 não me deixam mentir, direita radical e esquerda radical sempre cultivaram enorme pessimismo com relação ao instrumento "voto" e sua massificação como mecanismos centrais de formação e controle dos governantes. E basicamente pelo mesmo motivo: descrença na capacidade dos pobres em promover a boa escolha no momento da decisão. A primeira, por se considerar, por uma questão de nascimento, classe e, em alguns casos mais graves, cor, superior; a segunda, essencialmente pela iluminação adquirida através do doutrinamento. Ambas, quando na direção do processo histórico, levam ao desastre social, econômico e político das nações.

\section{A CONTRIBUIÇÃO dO JUDICIÁRIO}

A caracterização do sistema político brasileiro como basicamente corrupto encontrava-se de alguma maneira dispersa na conversa do dia a dia, caracterização sempre feita em meio a considerações sobre a complexidade do fenômeno político e sempre em meio a fórmulas mágicas de saneamento e solução. Digo "encontrava-se" porque 
em meados de 2012, por ocasião do julgamento do assim chamado "Mensalão", ministros do Supremo Tribunal Federal, instância máxima do Poder Judiciário brasileiro, vocalizaram aquilo que era apenas juízo mal formulado e genérico do cidadão comum sobre o funcionamento de nossas instituições.

Uma boa abordagem científica sobre o tema das relações entre Legislativo e Judiciário no Brasil contemporâneo encontra-se em Judicialização ou representação? Política, direito e democracia no Brasil, de Thamy Pogrebinschi. No trabalho, a autora trata do chamado fenômeno da "judicialização da política", tema recorrente em artigos e livros recentes no campo das ciências sociais. Em geral, os acadêmicos tratam as decisões do trabalho do Judiciário ao interpretar a Constituição como exercício contramajoritário, usurpação das funções do soberano - o povo, em tese legítima e exclusivamente representado pelo Congresso Nacional. É objeto também de inúmeras matérias e artigos jornalísticos, quase sempre seguindo o mote de acordo com o qual a intervenção dos juízes e, em particular, do Supremo Tribunal Federal, na esfera política decorreria da fraqueza de nosso Poder Legislativo. Em ambas as teses, temos, como fio condutor, a noção segundo a qual as instituições da representação política viveriam grave crise, sendo a judicialização artifício utilizado pela sociedade civil visando defender seus interesses e aspirações fundamentais ante uma maquinaria institucional hostil e injusta.

Pogrebinschi promoveu levantamento minucioso sobre quantidade, tipos, temas tratados, conteúdo das sentenças proferidas pelos juízes, além de uma bem organizada periodização do uso dos principais instrumentos à disposição do STF para modificar políticas adotadas pelo Legislativo e posteriormente sancionadas pelo Executivo. Analisou também as reações expressas em proposições legislativas promanadas do Congresso após as decisões finais do Supremo. Resultou cristalino que não é possível manter a tese de que o Judiciário age no vácuo deixado pelo Legislativo a respeito de questões relevantes da agenda pública. Foi desmentida, ademais, a proposição de que o STF seria instituição contramajoritária, sempre pronta a impedir que decisões de baixa qualidade eventualmente viessem a ser tomadas pelo legislador.

Um Legislativo que não trata de temas relevantes e que, quando o faz, exerce sua prerrogativa de maneira equivocada é, portanto, um mito. Não há, em suma, por que manter a ideia de uma superioridade técnica e moral do Judiciário, composto de agentes iluminados, esclarecidos, sempre dispostos a zelar pelo bem público e proteger a vontade geral de ataques desferidos pelos políticos profissionais, oriundos da escolha popular através do voto. 
[4] Limongi, Fernando. "Em defesa do Congresso". Valor Econômico, o1/05/2013.
Não obstante, se o cenário das relações horizontais é, em seu conjunto, mais equilibrado do que sugere a cobertura midiática de nossa política, a versão da superioridade dos juízes tem gerado consequências importantes. Basta refazer a trajetória de intervenções promovidas pelo Judiciário nas regras de competição eleitoral e partidária para notar que a mesma fantasmagoria a respeito do funcionamento das instituições democráticas brasileiras, que vige em amplos segmentos da sociedade, acabou atingindo boa parte dos juízes e ministros de nossos Tribunais Superiores. O episódio da verticalização das coligações, imposta a partir de consulta feita ao TSE sobre regras de composição de alianças eleitorais, demonstra bem o ponto. A poucos meses das eleições de 2002, o Judiciário decidiu que coligações partidárias articuladas em âmbito nacional não poderiam entrar em contradição com alianças feitas no âmbito estadual. Inócua e casuística, a medida apenas agravou a inevitável influência, em um país federativo de proporções continentais, dos fatores regionais na disputa nacional. O mesmo afã intervencionista, estimulado por visão equivocada de nossas instituições, se repete, como muito bem notou o cientista político Fernando Limongi, no caso da interpretação do STF que impôs a fidelidade partidária4 ${ }^{4}$ O Tribunal acabou flagrado em contradição após conceder ao recém-criado PSD o mesmo acesso ao fundo partidário e tempo no horário gratuito de propaganda eleitoral de partidos existentes desde antes da introdução da regra da fidelidade.

Nada mais assustador, porém, do que as falas e as narrativas sobre a política brasileira emanadas de alguns ministros quando do julgamento da Ação Penal 407, o assim chamado "Mensalão". Não se trata aqui exatamente de opinar sobre o conteúdo da decisão, de resto adequadamente comentado pelo recém-empossado ministro da Corte, o jurista Luiz Roberto Barroso, como um ponto fora da curva, tendo em vista a tradição "garantista" do STF, a escassez de provas para comprovar a culpabilidade de vários dos réus e a utilização não criteriosa da teoria do domínio do fato como embasamento das sentenças. O que de mais grave ficou foi o modo degradante e distorcido pelo qual as instituições partidárias foram tratadas em diversos momentos do processo. A cobertura, em tempo real, transmitida para milhões de espectadores não apenas corroborou o diagnóstico protofascista, cultivado por segmentos da elite brasileira a respeito das instituições de nossa democracia. Conferiu respeitabilidade e despudor às visões segundo as quais os políticos eleitos seriam criminosos, "quadrilheiros", membros de organizações mafiosas dotadas do único intuito de assaltar os cofres públicos e o bolso dos contribuintes. 


\section{AS MANIFESTAÇÕES E A RESPOSTA DO GOVERNO}

A resposta do governo à onda de protestos consistiu basicamente na apresentação de cinco "pactos" ao país, versando sobre responsabilidade fiscal, reforma política, mobilidade urbana, saúde e educação. De certa maneira, sem o desejar, o assessoramento político presidencial acabou por endossar a visão pouco lisonjeira sobre nossas instituições representativas, cultivada tanto na common parlance quanto nas cortes do Supremo. Falemos inicialmente dos pactos. Em verdade, apenas o tema da mobilidade urbana surge como novidade no cenário de políticas em torno das quais o Estado brasileiro é instado a criar alternativas consensuais e consistentes. Todo o resto faz parte de um conjunto de pontos, em alguma medida, já pactuados pela sociedade. A lei de responsabilidade fiscal foi aprovada $e$ tem sido a âncora institucional do consenso em torno da necessidade de governar tendo o equilíbrio nas contas públicas como parâmetro básico de comportamento do agente público. O sus, assim como os diferentes fundos de financiamento dos ensinos básico e médio, expressa o desejo coletivo de avançar no que tange o acesso de todos os brasileiros aos direitos fundamentais à saúde e à educação. Avançar mais nesses itens é uma questão de governar bem. Não sendo boa a avaliação do governo em áreas consideradas vitais, reza o processo democrático consagrado em nossa Carta Constitucional de 1988, alternativas políticas são apresentadas e o eleitor opta por não reconduzir ao governo o partido ou a coalizão de partidos responsável pela administração do país.

A reforma política também é em boa medida objeto de um pacto, o de não promovê-la de forma açodada. Não mexer nas instituições a não ser de modo prudencial e por tentativa e erro tem sido a solução de equilíbrio dada a intensidade do conflito em torno da questão, além, sobretudo, da enorme incerteza proveniente de eventuais mudanças nas regras que regem nosso processo eleitoral. Tal equilíbrio não advém do receio de parlamentares de mudarem as regras pelas quais se elegeram e das quais, portanto, supostamente se beneficiaram. O raciocínio é tão simples e claro quanto falso. As taxas de renovação parlamentar no Brasil são relativamente altas, donde decorre que nenhum político se sente seguro em sua cadeira de congressista. O problema de mudar é outro e mais profundo.

Em primeiro lugar, os parlamentares sabem que nenhuma reforma será capaz de preencher a expectativa existente em torno do tema. Não existe exemplo de reforma do sistema eleitoral que tenha reduzido taxas de corrupção no interior do sistema político. Assim, eleva-se o risco de no médio prazo, e no suposto da aprovação de uma reforma qualquer, aprofundar o descrédito popular nas institui- 
ções democráticas e confirmar ainda mais na mente de segmentos das elites o acerto da opção protofascista. Em segundo lugar, e talvez mais importante no horizonte de cálculo dos políticos, qualquer mudança de sistema produzirá efeitos incertos sobre suas condições de sobrevivência eleitoral. Sabe-se que mudanças de regimes majoritários para regimes proporcionais tendem a aumentar o pluralismo de partidos e, inversamente, a adoção de mecanismos majoritários acaba por reduzir a competitividade entre as agremiações. Todavia, os parlamentares, tomados individualmente, principalmente os do chamado baixo clero, não sabem ex ante se suas chances de vitória aumentam ou diminuem na transição de um sistema para outro, dado que estas dependem de diversos outros fatores associados à mudança que se encontram fora de seu controle imediato.

Não surpreende, portanto, a resistência encontrada pelo governo à ideia de submeter a plebiscito decisões que dizem respeito ao desenho do sistema eleitoral. É importante chamar a atenção para a falha no assessoramento político presidencial neste episódio em particular e não apenas pelo erro elementar de cálculo de timing e probabilidade de absorção pelo Congresso Nacional de ideia tão estapafúrdia. É também relevante notar que não poderia existir alvo mais equivocado para tratar de uma crise que se diz de representatividade.

Se existe algo na política brasileira de representativo, é a combinação de eleições presidenciais diretas e método proporcional para alocação de cadeiras na Câmara dos Deputados. É exatamente essa combinação que tem permitido algum avanço na cidadania desde o retorno à democracia com a constituinte de 1988. Aperfeiçoamentos podem ser obtidos na questão do financiamento de campanhas e em alguns pontos técnicos ligados à possibilidade de coligações e mecanismos de distribuição de sobras eleitorais. Todos esses itens já são objeto de debate e deliberação na Câmara e, no seu devido tempo, devem amadurecer e chegar ao plenário de maneira consensual. O resultado líquido, contudo, de enviar ao Congresso e anunciar à nação sobre a convocação de uma consulta em torno das instituições representativas é corroborar a visão segundo a qual a crise que se manifesta nas ruas tem origem no sistema de representação, quando na verdade o que está em jogo é a dimensão participativa da democracia.

Nada mais legítimo numa democracia do que a existência de protestos e manifestações de desagrado. O problema colocado no Brasil na atual conjuntura é o de sua intensidade, magnitude e reiteração, a ponto de colocar em risco valores democráticos importantes como a tolerância, a não violência e as liberdades mútuas. Trata-se, portanto, de uma questão de repensar os canais de interlocução entre setores, que por algum motivo não se sentem representados em suas preocupações básicas pela coalizão predominante no governo, e as entida- 
des do Estado responsáveis pela elaboração e efetividade de políticas públicas fundamentais. Mais criatividade e imaginação institucional no âmbito participativo e menos chavão institucionalista no âmbito representativo deve ser o norte da resposta política do governo à crise. Uma resposta cujo ponto de partida esteja assentado na defesa da solidez de nossas instituições representativas e democráticas.

\section{O EQUívOCO DA TRANSMUTAÇÃO BOLIVARIANA}

Uma leitura atenta da estratégia política de parte da esquerda brasileira tenderá a mostrar que se vive a ilusão de que o Brasil pode estar passando por um momento "bolivariano". Em países como Bolívia, Venezuela e Equador referendos, plebiscitos e novas Constituições têm sido utilizados como instrumento de resolução de impasses políticos entre uma nova elite que se forma a partir da inclusão de grupos secularmente excluídos do processo social e tradicionais proprietários dos recursos econômicos e de poder. Talvez seja esta a origem da ênfase dada ao plebiscito e à convocação de "assembleias constituintes exclusivas" como meio de encaminhar alguma solução para a recente onda de protestos. Ora, o rico experimentalismo institucional vivenciado por esses países radica em causas históricas muito concretas, relacionadas, sobretudo, a economias muito pouco sofisticadas e concentradas, a um tecido social relativamente pouco complexo e um sistema partidário até pouco tempo baseado num pacto de elites que excluía os temas da redistribuição e da inclusão no rol de preocupações do Estado. Não devemos perder tempo insistindo no abismo existente entre a trajetória do capitalismo brasileiro e a evolução econômica e social dessas nações.

O que vale comentar é o fato simples de ter sido o voto popular a origem das transformações sociais, econômicas e políticas pelas quais têm passado as diversas nações de nosso continente, sobretudo as mais pobres e desiguais. Foi a partir da eleição de presidentes e parlamentares comprometidos claramente com uma agenda de inclusão e redistribuição que a política na Bolívia, no Equador e na Venezuela vem experimentando tantas e tão admiráveis modificações. Reformar a Carta Constitucional, conferindo-lhe um perfil mais inclusivo, tem sido o encaminhamento possível para avançar nesse desiderato. No caso brasileiro, alternância de poder e a eleição de presidentes com perfis distintos das elites tradicionalmente dominantes já são parte da realidade política do país. Acresce-se a isso o fato de ser a Constituição de 1988 manifestação óbvia de um contrato social voltado para a inclusão. Finalmente, é também verdadeiro que diversas modificações na legislação infraconstitucional foram introduzidas e continuam a sê-lo, tendo em vista aprimorar os 
Recebido para publicação

em 19 de julho de 2013.

\section{NOVOS ESTUDOS}

CEBRAP

96, julho 2013

pp. 15-25 instrumentos com os quais o governo conta para tratar dos temas de educação, saúde e assistência social.

Mesmo no âmbito participativo a atual Carta Constitucional é extremamente inovadora e flexível no sentido da capacidade de absorver novos conteúdos, novas pautas e novos conflitos sociais a exigir alguma forma de acomodação no âmbito da agenda pública. A trajetória brasileira, em suma, é inteiramente diversa daquela que se observa em vizinhos no continente sul-americano, sobretudo, nos países andinos. Sendo distinta a trajetória, diferente há de ser a agenda necessária para avançar nos valores fundamentais de quem nasceu para a vida em um estado ditatorial e numa sociedade profundamente injusta, viveu a transição democrática e experimentou processos inequívocos de alternância no poder. $\mathrm{O}$ pacto inicial não pode ser outro senão o de manter e fortalecer aquilo que tem servido de mola propulsora fundamental ao processo brasileiro, contínuo e secular, de inclusão e redistribuição: as instituições representativas democráticas, consagradas na Constituição de 1988.

FABIANO SANTOS é professor e pesquisador do Instituto de Estudos Sociais e Políticos da Universidade do Estado do Rio de Janeiro. 